\title{
Processo de trabalho e condições de trabalho em frigoríficos de aves: relato de uma experiência de vigilância em saúde do trabalhador
}

\author{
Work process and working conditions in poultry processing plants: \\ report of a survey on occupational health surveillance
}

Paulo Antonio Barros Oliveira ${ }^{1}$

Jussara Maria Rosa Mendes ${ }^{2}$

${ }^{1}$ Programa de PósGraduação em Saúde Coletiva, Centro de Documentação, Pesquisa e Formação em Saúde do Trabalho. Universidade Federal do Rio Grande do Sul (UFRGS). Rua Ramiro Barcelos 2600/424, Rio Branco. 90035-003 Porto Alegre RS Brasil. pbarros@ufrgs.br

${ }^{2}$ Programa de PósGraduação em Saúde Coletiva, Núcleo de Estudos e Pesquisa em Saúde e Trabalho, UFRGS
Abstract This article presents the report of a survey on health surveillance activities performed in poultry processing plants in the south of Brazil. It aims to contribute to an understanding of the work process developed, the growth of the sector, the organization of labor and the confrontation with the economic model of this sector, which has been exposing employees to working conditions that undermine their health. The working conditions identified are considered largely incompatible with health and human dignity. The study supports interinstitutional intervention, especially with the Public Ministry of Labor, criticizes the weak implementation of specific government interventions in health conditions in the industry and introduces the new Regulatory Standard 36 as a positive perspective for the near future.

Key words Poultry processing plant, Health surveillance, Occupational health
Resumo Este artigo apresenta o relato de uma experiência de atividades de vigilância em saúde desenvolvidas em frigorificos de aves no sul do Brasil. Tem como objetivo apresentar subsídios para compreender o processo de trabalho desenvolvido, o crescimento do setor, a organização do trabalho, além do confronto com suas formas econômicas que vêm expondo trabalhadores a condições de trabalho que aviltam a saúde. As condições de trabalho identificadas são consideradas, em grande parte, incompatíveis com a saúde e com a dignidade humana. O presente estudo valoriza a intervenção interinstitucional, notadamente com o Ministério Público do Trabalho, critica a fraca implementação de intervenções concretas do Estado nas condições de saúde no setor e apresenta a nova Norma Regulamentadora 36 como perspectiva positiva para um futuro próximo.

Palavras-chave Frigorífico de aves, Vigilância em Saúde, Saúde do trabalhador 


\section{Introdução}

Os agravos à saúde do trabalhador se desenvolvem histórica e socialmente decorrentes do crescimento econômico e da diversificação dos processos produtivos. A intensificação das atividades do setor frigorífico traduziu-se na instalação de novas unidades fabris, na incorporação de unidades de todos os portes para a constituição de grandes grupos econômicos, no aumento de empregos formais e, além disso, no aumento de acidentes e doenças relacionados com o trabalho.

Os dados estatais disponíveis sobre morbimortalidade relacionadas ao trabalho não são fontes fidedignas da realidade do quadro de violência neste ramo industrial. Várias tentativas têm sido realizadas para tentar a redução do sub -registro dos acidentes e das mortes por acidentes de trabalho ${ }^{1}$. Entraves políticos para a implantação da Vigilância em Saúde de forma integral são identificados tanto na renovação institucional, na arena de conflitos de interesses, como na distância entre políticas formuladas e instituídas, e nas lacunas referentes à gestão do trabalho e à insuficiência do financiamento ${ }^{2}$.

A Vigilância em Saúde em determinado ramo da economia, no caso em tela da agroindústria de abate e processamento de aves, não foge das questões consideradas cruciais para a implantação da mesma no SUS 3 : (a) ausência de uma efetiva Política Nacional de Saúde do Trabalhador que coloque um marco conceitual claro, apresente diretrizes de implementação e proponha estratégias e planos de ação e de avaliação para efetivá-la; (b) fragmentação e dispersão da produção científica da área, prejudicando a importante colaboração que a Academia poderia oferecer para fundamentar as necessidades dos agentes políticos, movimentos sociais, gestores e profissionais de saúde; e (c) enfraquecimento e pouca capacidade de pressão dos movimentos sociais e dos trabalhadores, evidenciando a falta de qualificação das demandas, diante dos desafios do momento presente do mundo do trabalho no Brasil.

Como refere Machado, a intervenção em Vigilância em Saúde do Trabalhador (VST), deve acontecer dentro de uma práxis social transdisciplinar em que distintos atores se organizam em um processo heterodoxo e construtivista. Destacamos o momento histórico institucional vivido pelo Brasil nas últimas décadas e a necessidade da constituição de redes de VST a partir de objetos priorizados, no caso os frigoríficos, e em um campo de contradições entre a saúde e a produção como valores sociais ${ }^{4}$.

\section{A agroindústria brasileira: os frigoríficos como setor produtivo}

No Brasil, o setor de beneficiamento e produção de carne evoluiu muito nas últimas décadas. As exigências para a redução dos ciclos de vida útil dos produtos tornam-se imprescindíveis e o processo de trabalho capitalista não escapa desse intuito, ultrapassando seus limites, uma vez que os da força de trabalho também se tornam reduzidos. Como refere Antunes ${ }^{5}$, a competitividade exacerbada impõe ritmos acelerados, considerando que "os capitais não têm outra opção, para sua sobrevivência, senão inovar ou correr o risco de ser ultrapassados pelas empresas concorrentes".

Diante desse contexto, a indústria do país passou a implementar medidas de modernização com a finalidade de reduzir custos, como a reorganização da produção; a aquisição de novos equipamentos; a inovação dos produtos; os ganhos em escala; as mudanças nas estratégias de relacionamento fornecedor/cliente; o melhoramento qualitativo da matéria-prima; a flexibilização das relações de trabalho; além da implementação de técnicas de controle de qualidade, entre outros $^{6}$. Mas, recentemente, Marques ${ }^{7}$ questiona a visão de uma inevitabilidade dos processos de segmentação e precarização das relações de trabalho e emprego, responsáveis pela inscrição de "novas" formas de desigualdade social que alicerçam o atual modelo de desenvolvimento das economias e sociedades, onde os frigoríficos brasileiros se inserem.

Assim, de uma situação pouco expressiva em décadas anteriores, esse ramo industrial desponta no mercado de trabalho, a partir de 1990, com potencial geração de emprego e renda ${ }^{8}$. Segundo a União Brasileira de Avicultura / $\mathrm{UBABEF}^{9}$, a avicultura emprega aproximadamente 3,6 milhões de pessoas, direta e indiretamente, respondendo por quase $1,5 \%$ do Produto Interno Bruto (PIB) nacional. O setor é representado por dezenas de milhares de produtores integrados, centenas de empresas beneficiadoras e dezenas de empresas exportadoras localizadas no interior do país, principalmente nos Estados das regiões Sul e Sudeste. Em muitas dessas regiões, a produção de frangos é a principal atividade econômica. $\mathrm{O}$ Brasil situa-se entre os três maiores produtores mundiais de carne de frango, juntamente com os Estados Unidos e a China.

A evolução da avicultura na agroindústria brasileira atingiu um crescimento exponencial expresso na produção com a marca histórica de 13,058 milhões de toneladas em 2011, dos quais 
cerca de 69\% foram distribuídos no mercado interno. $\mathrm{O}$ consumo de carne de aves no Brasil alcança patamares de aproximadamente 39 quilos per capita ao ano, o que indica que o "consumo do frango industrial produziu modificações nos hábitos de consumo popular"10.

Destaca-se ainda que o Brasil mantém, desde 2004, a posição de maior exportador mundial de carnes de aves, com a marca de 3,9 milhões de toneladas embarcadas para mais de 150 países em todos os continentes. O setor apresenta-se como terceiro produtor nas exportações do agronegócio e quinto na pauta brasileira de exportação, sendo que a participação no mercado mundial chega aos $45 \%{ }^{5}$.

As implicações do crescimento do setor frigorífico também se expressam no perfil dos trabalhadores a serem contratados, marcadamente pessoas mais qualificadas, treinadas e com disponibilidade de flexibilização para atuar nas empresas. A qualificação profissional torna-se, desta forma, importante atributo para a inserção e a permanência dos trabalhadores nos postos de trabalho ${ }^{11}$. No entanto, resultados de estudos realizados no Paraná apontam que "o nível de escolaridade não é priorizado na contratação da maioria dos trabalhadores, daqueles operadores que vão atuar na produção e há a existência de um grande contingente de trabalhadores com ensino fundamental incompleto" ${ }^{11}$.

Tais resultados evidenciam que os indicativos de aprimoramento das formas de produção e acumulação do capital, com alterações na forma de organização dos processos de trabalho, vão sendo implantados de forma desigual, especialmente para os trabalhadores que devem garantir uma produção com qualidade, que atenda às necessidades das demandas e às normas de vigilância sanitária. Este mesmo estudo revela ainda que "dois elementos são decisivos para a contratação de novos trabalhadores para a empresa frigorífica em questão: o bom estado de saúde e a disposição pessoal para suportar o tipo e a intensa rotina de trabalho"11.

As exigências para a inserção dos trabalhadores são, portanto, ter condições de saúde para o desempenho de tarefas repetitivas, desgastantes e insalubres, demonstrando a centralidade da saúde no processo de seleção dos trabalhadores, para além da habilidade prévia e do seu nível de escolaridade. "A produção não requer, obrigatoriamente, trabalhadores absolutamente saudáveis, mas que o sejam o suficiente para garantir a produtividade esperada. O que importa não é a saúde do trabalhador, mas a saúde necessária à produção"12.
Assim, a precarização do e no trabalho ${ }^{13}$ expressa a nova ofensiva do capital sobre este, na qual o que é preservado é o aumento dos lucros por parte das empresas. Constata-se que essa ofensiva significou "a restauração das formas de exploração dos trabalhadores que o capitalismo parecia ter superado" 14 .

As atuais condições de trabalho são consideradas, em muitas ocasiões, incompatíveis com a saúde e com a dignidade humana. $\mathrm{O}$ modo de produção remonta ao tempo de Henry Ford, influenciado na concepção das linhas de montagem automobilística. Há uma verdadeira legião de lesionados, sobretudo trabalhadores jovens ${ }^{15,16}$. Nestas décadas de evolução acelerada, o ramo de negócios evoluiu muito em questões de ordem sanitária, mas muito pouco em seus princípios e concepções iniciais quanto ao modelo de produção. Estudos do Canadá17, já em 1993, identificavam que no modelo produtivo implementado nos frigoríficos havia uma elevada prevalência dos agravos associados com o aumento da intensidade do trabalho, da hipersolicitação.

Os trabalhadores atuam em uma sequência atroz, com um ritmo de produção de cadência elevada, determinando, consequentemente, um ritmo elevado do trabalho, que, por sua vez, ocasiona a prevalência de agravos relacionados com a repetitividade e a sobrecarga muscular. Aliado a este fator, há a predominância de um Sistema Taylorista-Fordista de produção, com todas as suas mazelas de fragmentação, baixa qualificação, atividades fixas e pouco variáveis, pouca remuneração e redução de todos os tempos mortos, monotonia, acumulação de tarefas desinteressantes, limitação dos contatos humanos, entre outros. Pode-se afirmar que nos dias atuais não é possível trabalhar mais rápido do já imposto. Aliado a este quadro de modelo produtivo, temos o trabalho permanente em ambiente frio (até o máximo de $12^{\circ} \mathrm{C}$ ), além do ruído elevado (frequentemente acima de $90 \mathrm{~dB}(\mathrm{~A}))$, da exposição à umidade e a riscos biológicos (carne, glândulas, vísceras, sangue e fezes).

Cabe ressaltar que as atividades, em sua grande maioria, são desenvolvidas em áreas refrigeradas, sempre com temperaturas inferiores aos $12^{\circ} \mathrm{C}$, nas quais nenhum equipamento de proteção individual (EPI) pode ser eficiente o bastante para proteger os trabalhadores das consequências de um ambiente insalubre, notadamente para as vias respiratórias ${ }^{16}$.

Neli, em seu estudo, identifica que a organização do trabalho fundada nos preceitos taylorista/fordista predominante no setor, foi acrescida 
por outras técnicas de organização da produção e do trabalho, inspiradas no modelo japonês ou toyotista, e que estão interferindo nas condições de saúde dos trabalhadores tanto física quanto psiquicamente. $\mathrm{O}$ crescimento de casos de LER (Lesão por Esforço Repetitivo) na categoria aparece de forma destacada como consequência ${ }^{18,19}$.

Outros riscos no processo produtivo são o forte constrangimento em relação às posturas inadequadas dos membros superiores, tronco e cabeça (elevação dos ombros, inclinação do tronco, extensão do pescoço) e ao trabalho estático. Isso ocorre devido à postura fixa de pé, como na linha de corte e desossa, e também ao trabalho dinâmico dos membros superiores e inferiores em outras atividades, como no transporte individual de cargas, no manuseio de peças de cortes, entre outras. Também há a exigência de força no manuseio de produtos que se sobrepõe à temperatura na qual eles precisam ser mantidos, entre $2^{\circ}$ e $3^{\circ} \mathrm{C}$ na superfície do produto que está sendo manipulado. E, por fim, ao trabalho preponderantemente em pé associam-se os espaços exíguos que impedem a livre movimentação em várias plantas, notadamente nas mais antigas ${ }^{20}$.

Além disso, a cadência elevada imposta pela gerência, que escolhe a velocidade das máquinas, leva à quase impossibilidade de os trabalhadores determinarem o ritmo e exercerem seus direitos a pausas. Em alguns casos, chega-se a identificar um volume de movimentos repetitivos assustadores, como no cortar e abrir as coxas/sobrecoxas da carcaça. Nesta atividade, foi identificada, em um único trabalhador, a produção de 17 frangos por minuto, com quatro movimentos por frango (três cortes), totalizando 68 movimentos por minuto, 4.080 movimentos por hora, 35.000 movimentos por dia. Já a atividade de separação da coxa e da sobrecoxa desossada, com ambas as mãos, resultou em 30 peças por minuto, com quatro movimentos por peça, totalizando, desta forma, 120 movimentos por minuto, 7.200 movimentos por hora, e 63.000 movimentos por $\mathrm{dia}^{16}$.

Sobrepõe-se a esta sobrecarga biomecânica o estresse da gestão do trabalho que usa estratégias rígidas, que impõe metas sobredimensionadas, que levam a sobrecargas psicofisiológicas que interferem em suas capacidades sensitivas, motoras, psíquicas e cognitivas, destacando, entre outras, questões relativas aos reflexos, à postura, ao equilíbrio, à coordenação motora e aos mecanismos de execução dos movimentos que variam intra e inter indivíduos ${ }^{21}$.

Como agravantes desse modelo produtivo temos ainda a omissão em reduzir os riscos, por parte do corpo técnico das empresas, que não correlacionam o ritmo excessivo, a ausência de pausas e o elevado tempo de exposição, com jornadas de até 15 horas, resultando em agravos de saúde de seus trabalhadores.

\section{A Vigilância em Saúde do Trabalhador em unidades de processamento de carnes}

Os frigoríficos não são iguais entre si. Eles apresentam diferenças relevantes uma vez que trabalham com diferentes fontes de matéria-prima (aves, suínos, bovinos, ovinos, peixes, entre outros). Além disso, até mesmo entre duas unidades de uma mesma empresa, com o mesmo tipo de abate, são encontradas diferenças.

Assim, os resultados deste estudo são apresentados de forma a valorizar as questões consideradas mais importantes e relevantes segundo os critérios de frequência e de gravidade. Tem-se o conhecimento de que as discussões têm como finalidade contribuir para as análises da temática e que não esgotam as interfaces que contribuem para o agravamento da questão social neste âmbito ${ }^{20}$.

Na presente experiência, os casos de intervenções mais produtivas em termos de promotora de modificações reais nos ambientes de trabalho foram aqueles onde havia maior integração interinstitucional. Os órgãos mais atuantes foram o Ministério do Trabalho e Emprego, em articulação com o Ministério Público do Trabalho. Os Centros de Referência em Saúde do Trabalhador (Cerest) foram mais atuantes em matadouros municipais e em estabelecimentos maiores nos Estados do sul do país, a partir de um processo de formação de seus técnicos, transcorrido em 2013.

Nas inspeções realizadas em fábricas, antes da entrada no ambiente de trabalho, é interessante conhecer a empresa a partir do que ela comunica de si mesma. Nos dias atuais, é importante visitar o site da empresa, conhecer o seu perfil de produção, a evolução deste perfil nos últimos anos, conferir o perfil dos seus clientes, e verificar, até mesmo, a evolução de suas ações na Bolsa de Valores. Os analistas de mercado, às vezes, conseguem antever situações de produção da empresa que um leigo no assunto nem imagina. Outra fonte importante de informações são os dados do Instituto Nacional de Seguro Social (INSS). Notificada, a gerência regional do Instituto encaminha dados sobre os trabalhadores afastados por motivo de acidente ou doença em geral e os acidentários, segundo os diagnósticos ${ }^{20}$.

Durante a realização do trabalho de vigilância, é importante atentar principalmente para os 
acidentes graves, com maior período de afastamento, e os trabalhadores com lesões osteomusculares e distúrbios no campo da saúde mental. Incorporar os dados da Classificação Brasileira de Ocupações (CBO) facilita a análise. Além disso, também é de suma importância observar os setores com maiores incidências de ansiedade e depressão.

Quando a ida ao estabelecimento é decidida, é necessário ter conhecimento das ações que a empresa está realizando para a promoção da saúde e prevenção de doenças e acidentes de trabalho. Para tanto, é imprescindível a análise de programas de prevenção de acidentes, de Prevenção de Riscos Ambientais (PPRA), de Controle Médico de Saúde Ocupacional (PCMSO), de Combate a Incêndios (PCI), além de inspeção das caldeiras, de vasos sobre pressão e sistemas de refrigeração (mais frequentemente contendo amônia), de controle de pânico e emergências, entre outros que possam existir.

As empresas possuem diferentes abordagens e, em muitos casos, estes mesmos planos e programas podem ter nomes diferentes, mas abordam esses mesmos aspectos, uma vez que são determinações obrigatórias por diferentes legislações, de diferentes campos de atuação do Estado. A não existência de um ou de alguns destes já é forte indicativo do nível de interesse da organização com as questões de Saúde e Segurança do Trabalho (SST).

Outro elemento importante é verificar se a composição do Serviço Especializado em Segurança e Medicina do Trabalho (SESMT) está completa e se seus membros possuem a habilitação necessária. Não é raro encontrar profissionais contratados sem a obrigatoriedade de cumprir com a carga horária da jornada, ou a adequada comprovação da habilitação técnica, como o registro da especialidade no respectivo conselho profissional. As empresas não estabelecerem a dedicação mínima de horas diárias de atividade para o Médico do Trabalho e para o Engenheiro de Segurança, bem como o SESMT acaba por não estender a assistência dos serviços a todos os trabalhadores do estabelecimento, inclusive das empresas contratadas. Nos relatórios elaborados pela empresa, identifica-se que o Serviço Especializado não analisa e não registra em documentos específicos todos os acidentes ocorridos na empresa ou estabelecimento, com ou sem vítima. Também não se encontram registrados todos os casos de doença ocupacional, os fatores ambientais, as características do agente e as condições do(s) indivíduo(s) portador(es) de doença ocupacional ou acidentado, incluindo análise das causas. Percebe-se que ainda é frequente o enfoque centrado em ato ou condição insegura.

Também torna-se imprescindível analisar as atas da Comissão Interna de Prevenção de Acidentes (CIPA), identificando se há a relação dos conteúdos com o tamanho da empresa, sua complexidade, se os fatos ali narrados não são repetitivos, fator este que identificaria que a organização não dá andamento às solicitações da CIPA ou não valoriza suas ações.

Outro ponto identificador do nível de interesse em SST da administração superior é a liberação, periodicamente, dos membros da CIPA de suas atividades de produção para a realização de inspeções de segurança ou acompanhamento das análises de acidentes realizadas pelo SESMT, por exemplo. Conferem-se ainda as assinaturas dos membros da comissão que analisam os acidentes com a composição da CIPA.

Todas estas informações irão compor o rol de evidências que delineará a compreensão que o avaliador destas ações terá das condições ambientais, bem como do nível de envolvimento da direção superior da organização nas questões de SST.

$\mathrm{Na}$ inspeção propriamente dita, do ponto de vista trabalhista, é frequente deparar-se com situações nas quais a empresa não concede ao empregado um descanso semanal de 24 (vinte e quatro) horas consecutivas, nos termos do art. 67, caput, da Consolidação das Leis do Trabalho (CLT), bem como deixar de efetuar o pagamento integral do salário mensal devido ao empregado até o $5^{\circ}$ (quinto) dia útil do mês subsequente ao vencido (art. 459, $\$ 1^{\circ}$, da CLT).

Outra situação encontrada com certa frequência é o não pagamento do período de troca de roupa pelo uniforme e vice-versa como hora trabalhada. Está consolidado o entendimento de que este período, por ser imprescindível ao processo produtivo, deve ser pago como hora trabalhada. Neste sentido, encontram-se frigoríficos que colocam o cartão de ponto na entrada do prédio da produção, enquanto que o vestiário fica próximo da entrada do estabelecimento, e os trabalhadores não recebem por este período de troca de roupas e de deslocamentos, às vezes longos e demorados, tanto na entrada como na saída.

As empresas deixam de cumprir diversas disposições legais sobre segurança e saúde, iniciando por deixar de informar aos trabalhadores os riscos que possam originar-se nos locais de trabalho. As desconformidades com as normas brasileiras vão desde questões ligadas à segurança nas máquinas, passando pelas ligadas à higiene 
e chegando àquelas vinculadas à organização do trabalho e do processo produtivo, notadamente a cadência elevada da produção, que leva ao ritmo muito acelerado, acima da capacidade humana de recuperação fisiológica e psicológica. Até bem pouco tempo, as empresas não ofereciam as condições de realização das pausas pelo trabalho em ambiente frio, determinadas pelo artigo $253 \mathrm{da}$ CLT (trabalho em frigorífico), de pelo menos 20 minutos de pausa a cada $1 \mathrm{~h} 40 \mathrm{~min}$ trabalhada.

É comum encontrar pisos, escadas, rampas, corredores e passagens dos locais de trabalho que não apresentam a limpeza permanente adequada, que deveria evitar o acúmulo de material proveniente do processo produtivo, tal como vísceras e sangue, ou qualquer outra substância como graxas e óleos que possam torná-los escorregadios. Constata-se ainda que nos locais onde há perigo de escorregamento, não são empregados materiais antiderrapantes. Além disso, as áreas de circulação e os espaços em torno de máquinas e equipamentos não são dimensionados para que o material, os trabalhadores e os transportadores mecanizados possam movimentar-se com segurança. Também não há distância mínima de separação das máquinas, sendo que deveria haver áreas reservadas para corredores e armazenamento de materiais devidamente demarcadas com faixa nas cores indicadas pelas normas técnicas.

Outro problema grave, pelas consequências que podem advir de sua não realização, é o fato destas unidades produtivas não atenderem o mínimo das condições estabelecidas em norma para trabalho em plataformas e em altura, como: a) guarda-corpos e rodapés em boas condições e dentro das especificações; b) acesso seguro, o que inclui as escadas em boas condições, com corrimão e, no caso de escadas tipo marinheiro, gaiolas protetoras; c) uso de linhas de vida projetadas e dimensionadas adequadamente, além de cintos de segurança e trava-quedas, onde necessário. $\mathrm{O}$ trabalho em altura superior a dois metros exige a prévia análise dos riscos e, quando necessário, a Permissão de Trabalho, realizada por técnicos habilitados.

Os Programas de Prevenção ${ }^{22}$ devem ser parte integrante do conjunto mais amplo das iniciativas da empresa no campo da preservação da saúde e da integridade dos trabalhadores, e estar articulado com o disposto nas demais normas vigentes, em especial com o PCMSO (NR $7)^{23}$ e a Ergonomia (NR 17) ${ }^{24}$. Estes programas raramente contam com um planejamento anual mais detalhado, com o estabelecimento de metas específicas, prioridades e cronograma, estratégia e metodologia de ação, registro, manutenção e divulgação de dados, periodicidade e forma de avaliação e registro.

Nesse planejamento, segundo as normas vigentes, devem constar, no mínimo, ações que digam respeito ao número de trabalhadores expostos ao risco de acidente, inclusive com a execução de um plano de emergência e de fuga, incluindo treinamento periódico dos trabalhadores.

Um dos principais itens de um programa de prevenção, e raramente seguido pelas empresas, é a obrigatoriedade de adoção de medidas necessárias e suficientes para a eliminação, a minimização ou o controle dos riscos ambientais, sempre que forem verificadas uma ou mais das seguintes situações: a) quando há a identificação de risco potencial à saúde na fase de antecipação; b) quando há a constatação de risco evidente à saúde na fase de reconhecimento, c) quando os resultados das avaliações quantitativas da exposição dos trabalhadores excederem os valores dos limites previstos na NR 15 ou, na ausência destes, os valores limites de exposição ocupacional adotados pela American Conference of Governmental Industrial Higyenists-ACGIH, ou aqueles que venham a ser estabelecidos em negociação coletiva de trabalho, desde que mais rigorosos do que os critérios técnico-legais estabelecidos.

A NR 15, para fins de prevenção, é utilizada quando os valores forem acima dos níveis de ação (metade dos níveis de tolerância). Mas, bem antes disso, quando na fase de projeto e de planejamento têm-se condições de antecipação sobre a existência de risco potencial à saúde, já há a obrigatoriedade de adoção de medidas necessárias e suficientes para a eliminação, a minimização ou o controle dos riscos ambientais. E, na quarta opção, quando através do controle médico da saúde ficar caracterizado o nexo causal entre danos observados na saúde dos trabalhadores e a situação de trabalho a que eles ficam expostos. Basta um diagnóstico de nexo causal para haver a obrigatoriedade de adoção de medidas necessárias e suficientes para a eliminação, a minimização ou o controle dos riscos ambientais. Há uma conduta em desconformidade total com a legislação, de somente iniciar uma ação de prevenção quando há a aferição de concentrações acima de limites de tolerância.

Quanto ao PCMSO, estes devem seguir as diretrizes determinadas na norma para sua elaboração e implementação, que são, obrigatoriamente: a) considerar as questões incidentes sobre o indivíduo e a coletividade de trabalhadores, privilegiando o instrumental clínico-epidemio- 
lógico na abordagem da relação entre sua saúde e o trabalho; b) ter caráter de prevenção, rastreamento e diagnóstico precoce dos agravos à saúde relacionados ao trabalho, inclusive de natureza subclínica, além da constatação da existência de casos de doenças profissionais ou danos irreversíveis à saúde dos trabalhadores; e c) ser planejado e implantado com base nos riscos à saúde dos trabalhadores, especialmente os identificados nas avaliações previstas nas demais normas.

No campo da segurança em máquinas, podemos afirmar que são raras as situações encontradas nas quais todas as máquinas de um estabelecimento atendam à Norma Regulamentadora 12 de proteção destas. Encontram-se, ainda, casos de situações elementares, como a não manutenção de aterramento das máquinas. Também não é raro encontrar máquinas que estão aterradas aparentemente, pois o sistema de aterramento é incompleto, sem continuidade do fio terra até o dispositivo próprio e adequado junto ao solo.

Nos dias atuais, a segurança em máquinas e equipamentos não deve ser pensada como um dispositivo. Existe a obrigatoriedade de que sejam pensados como sistemas com redundância, onde um dispositivo é interligado a outro, e todos são supervisionados por sistemas eletrônicos. Acidente com máquina e equipamento é indicativo de falta de segurança nos mesmos. Não há como manter-se a falácia da culpabilização dos trabalhadores e do famigerado ato inseguro.

Como referido inicialmente, não se pretende esgotar o assunto, mas contribuir com esse debate considerando a intensa reestruturação produtiva com impactos na vida e no mundo social do trabalhador. Apontam-se, neste relato, as questões que marcaram a experiência vivenciada na vigilância em saúde realizada em frigoríficos na região.

\section{NR-36 - possibilidades e limites da nova normatização}

A Norma Regulamentadora $36^{25}$ foi elaborada e aprovada por consenso por um comitê tripartite. Aconteceu graças ao esforço e à luta quase que permanente dos trabalhadores, às pressões de grandes grupos empresariais exportadores de carnes e derivados e a de um pequeno grupo de servidores públicos do Ministério do Trabalho e Emprego que há mais de dez anos tentava inserir as condições de trabalho nos frigoríficos em nosso ordenamento regulatório. Este é um bom exemplo de como as normas são construídas e se consolidam no Brasil. Sua edição representa um passo importante na tentativa de melhoria nas condições de trabalho neste ramo da produção.

Embora a obrigação de pausas para o trabalho em ambientes frios e refrigerados existisse na CLT desde a década de 1970, e as pausas para o trabalho com sobrecarga muscular estática ou dinâmica desde novembro de 1990, a NR 36 veio consolidar e detalhar melhor estas obrigações, daí a sua grande importância.

Outro avanço é a descrição clara e objetiva de que os programas de prevenção e de saúde das empresas têm que estar articulados entre si e com todas as normas. Por mais que pareça óbvio, mesmo sendo uma obrigação presente há várias décadas, o meio técnico empresarial ainda reluta contra esta articulação necessária, possuindo ainda uma visão distorcida de que os programas de saúde somente deveriam estar articulados com a Norma Regulamentadora 9, que trata dos riscos físicos, químicos e biológicos, dentro da visão de uma higiene do trabalho que também já está ultrapassada.

Durante este período pós-normatização, desenvolveu-se, em 2013, no âmbito do SUS, com o apoio da Fiocruz e com financiamento do Ministério da Saúde, um trabalho extenso de capacitação no Estado do Paraná. Em sete cidades distribuídas em todo Estado, servidores dos CEREST e das unidades de Vigilância em Saúde dos municípios da região foram capacitados na aplicação da NR 36. Em algumas destas ocasiões, participaram Procuradores do Trabalho e representantes dos trabalhadores. Aproximadamente trezentas pessoas acompanharam a atividade.

Em Santa Catarina, a Secretaria da Saúde utilizou uma estratégia diferente, promovendo uma capacitação de uma semana, com atividades práticas de inspeção em dois frigoríficos, destinada a trinta membros dos CEREST de âmbito estadual e municipal, de regiões nas quais os frigoríficos fossem importantes para sua economia. Após a inspeção nos locais de trabalho, os participantes discutiram as situações encontradas, compararam com a legislação e esboçaram a elaboração de relatórios de fiscalização.

A aplicação das normas tem seus limites e o mais evidente é a falta de articulação entre os órgãos do Estado encarregados de sua fiscalização. Ministérios do Trabalho e Emprego, da Saúde e da Previdência, passados um quarto de século da nova Constituição, ainda não definiram claramente seus espaços de atuação. Documentos, decretos, portarias às dezenas ainda não conseguem se expressar na prática diária como disposição institucional, o que não invalida os belos exem- 
plos de trabalhos articulados que existem pelo país, estes muito mais por características pessoais dos agentes públicos do que por definição política institucionalizada.

Outra limitação é o pequeno esforço de capacitação dos quadros dos agentes públicos. $\mathrm{Na} \mathrm{Au}-$ ditoria Fiscal do Trabalho, passados dois anos da publicação da NR 36, ainda não foi institucionalizada uma capacitação para seus quadros, nem localmente e nem geral, que abrangesse todo o país, como era de se esperar. No Sistema Único de Saúde (SUS) este esforço pode ser encontrado apenas nos Estados do Paraná e de Santa Catarina, no contexto da Macro Sul da Rede Nacional de Atenção Integral à Saúde do Trabalhador.

Os desafios são imensos considerando a intrínseca relação da saúde com o processo de trabalho e seus impactos nos modos de viver e morrer dos trabalhadores. A precarização do e no trabalho é um traço estrutural do modo de produção adotado. No atual contexto do trabalho nos frigoríficos de aves, essa situação apresentase em sua forma mais perversa, pois, além de tirar a saúde dos trabalhadores, com implicações para a família e sua vida, tira direitos de cidadania. A via de acesso, na maioria das vezes, é o recurso à judicialização dos direitos. As contradições pre- sentes neste espaço de trabalho, inter-relacionando avanços do capital e precarização do já precarizado trabalho desenvolvido pelos trabalhadores dos frigoríficos no Brasil expõe esta dura realidade na experiência aqui relatada.

\section{Colaboradores}

PAB Oliveira participou da análise dos relatórios e da reflexão geral sobre o tema. JMR Mendes participou da análise dos relatórios de inspeção e da reflexão geral sobre o tema. 


\section{Referências}

1. Drumond EF, Silva JM. Avaliação de estratégia para identificação e mensuração dos acidentes de trabalho fatais. Cien Saude Colet 2013; 18(5):1361-1365.

2. O'Dwyer G, Reis DCS, Silva LLG. Integralidade, uma diretriz do SUS para a vigilância sanitária. Cien Saude Colet 2010; 15(Supl. 3):3351-3360.

3. Gomez CM, Lacaz FAC. Saúde do trabalhador: novasvelhas questões. Cien Saude Colet 2005; 10(4):797-807.

4. Machado JMH. A propósito da Vigilância em Saúde do Trabalhador. Cien Saude Colet 2005; 10(4):987-992.

5. Antunes R. Os sentidos do trabalho: ensaio sobre a afirmação e negação do trabalho. $2^{a}$ ed. São Paulo: Boitempo; 2000.

6. Espíndola CJ. Tecnologia e novas relações de trabalho nas agroindústrias de carne do Sul do Brasil. Scripta Nova 2002; 6(119):1-7.

7. Marques APP. Reestruturação produtiva e recomposições do trabalho e emprego: um périplo pelas "novas" formas de desigualdade social. Cien Saude Colet 2013; 18(6):1545-1554.

8. Donda Júnior A. Fatores Influentes no Processo de Escotha da Localização Agroindustrial no Paraná: Estudo de Caso de Uma Agroindústria de Aves [tese]. Florianópolis: UFSC; 2002.

9. União Brasileira de Avicultura (UBABEF). Annual Report 2012. [acessado 2014 maio 29]. Disponível em: http://www.ubabef.com.br/files/publicacoes/41c30 a0f46702351b 561675f70fae077.pdf

10. França LR, Fernandes Filho JF. A evolução da avicultura de corte em Goiás. In: Pereira SL, organizador. O agronegócio nas Terras de Goiás. Uberlândia: Edufu; 2003. p. 175-211.

11. Finkler AL, Cêa GSS. Atuação dos Trabalhadores em frigoríficos da Região Oeste Do Paraná: As Qualificações Requeridas. In: Revista da RET. Estudos do Trabatho 2009: Ano III(5). [acessado 2014 maio 29]. Disponível em: http://www.estudosdotrabalho.org

12. Ribeiro HP. A violência oculta do trabalho: as lesões por esforços repetitivos. Rio de Janeiro: Fiocruz; 1999.

13. Machado JMH, Gomez CM. Acidentes de trabalho, concepções e dados. In: Minayo MC, organizadora. Os muito Brasis: saúde e população na década de oitenta. São Paulo, Rio de Janeiro: Ed. Hucitec, Abrasco; 1995. p. 117-142.

14. Netto JP, Braz M. Economia Política: uma introdução crítica. $2^{a}$ ed. São Paulo: Cortez; 2007. (Biblioteca básica de serviço social; v.1)

15. Neves MAB. As Doenças Ocupacionais e as Doenças Relacionadas ao Trabalho: as diferenças conceituais existentes e as suas implicações. São Paulo: Ed. LTr; 2011.

16. Brasil. Ministério do Trabalho e Emprego (MTE). Superintendência Regional do Trabalho e Emprego no Rio Grande do Sul. Seção de Segurança e Saúde no Trabalho - SEGUR. Relatório de Fiscalização do Trabalho - Doux Frangosul - Unidade de Montenegro/RS. Porto Alegre: MTE; 2010.
17. Institut de recherche en Santé et en securité du travail $\mathrm{du}$ Quebec. Problèmes musculosquelettiques et mouvements répétitifs dans les abattoirs de Volailles. Quebec: Raport; 1993.

18. Neli MA. Reestruturação produtiva e saúde do trabalhador: um estudo com os trabalhadores de uma indústria avícola [dissertação]. Ribeirão Preto: Universidade de São Paulo; 2006.

19. Ikedo F, Ruiz RC. Fazendo o nexo entre a doença e o trabalho. In: Ikedo F, Ruiz RC, organizadores. Trabalhar e Adoecer na Agroindústria: da reabilitação profissional à construção da Norma Regulamentadora NR 36. Florianópolis: Insular; 2014. p. 119-124.

20. Oliveira PAB. Uma introdução à Auditoria Fiscal em Frigoríficos. In: Ikedo F, Ruiz RC, organizadores. Trabalhar e Adoecer na Agroindústria: da reabilitação profissional à construção da Norma Regulamentadora NR 36. Florianópolis: Insular; 2014. p. 103-118.

21. Hutz CS, Zanona C, Brum Neto H. Adverse Working Conditions and Mental Illness in Poultry Slaughterhouses in Southern Brazil. Psicologia: Reflexão e Crítica 2013; 26(2):296-304.

22. Brasil. Ministério do Trabalho e Emprego. Portaria SSST n. ${ }^{\circ} 25$, de 29 de dezembro de 1994 . Norma Regulamentadora 9 - Programa de Prevenção de Riscos Ambientais. Diário Oficial da União 1994; $30 \mathrm{dez}$.

23. Brasil. Ministério do Trabalho e Emprego. Portaria no 24, de 29 de dezembro de 1994. Norma Regulamentadora 7 - Programa de Controle Médico e Saúde Ocupacional. Diário Oficial da União 1994; 30 dez.

24. Brasil. Ministério do Trabalho e Emprego. Portaria MTPS n. ${ }^{\circ}$ 3.751, de 23 de novembro de 1990. Norma Regulamentadora 17 - Ergonomia. Diário Oficial da União 1990; 26 nov.

25. Brasil. Ministério do Trabalho e Emprego. Portaria MTE n. ${ }^{\circ}$ 555, de 18 de abril de 2013. Norma Regulamentadora 36. Segurança e Saúde no Trabalho em Empresas de Abate e Processamento de Carnes e Derivados. Diário Oficial da União 2013; 19 abr.

Artigo apresentado em 29/08/2014

Aprovado em 29/08/2014

Versão final apresentada em 01/09/2014 
